Journal of Social Sciences 7 (4): 569-574, 2011

ISSN 1549-3652

(C) 2011 Science Publications

\title{
Factors Influencing Commitment of Volunteers' in Neighborhood Watch Organization
}

\author{
${ }^{1}$ V.B. Thomas, ${ }^{1}$ S. Selvadurai, ${ }^{1}$ A.C. Er, ${ }^{1}$ N. Lyndon and ${ }^{2}$ R. Moorthy \\ ${ }^{1}$ School of Social, Development and Environmental Studies, \\ ${ }^{2}$ School of History, Politics and Strategy, Faculty of Social Sciences and Humanities, \\ Universities Kebangsaan Malaysia, Bangi 43600, Selangor, Malaysia
}

\begin{abstract}
Problem statement: Social ties become less cohesive as society becomes urbanized. The need for social institutions to redress this state of affairs is crucial. There are two objectives of this research: (i) to examine the commitment level of volunteer residents participation in neighborhood watch organization and (ii) to identify attitudinal and motivational factors that influence their level of commitment. Approach: The study was carried out on a neighborhood watch organization called Rukun Tetangga (RT) Taman Sri Jelok, a suburban neighborhood in Kajang, located in the central part of Peninsular Malaysia. Data is collected via questionnaire administered through a census survey of 200 volunteer residents from the neighborhood watch organization. Data is analyzed using descriptive statistics and correlation techniques. Results: The research reveals high commitment level shown by volunteer residents in carrying out community activities, especially in undertaking mutual cooperation activities such as gotong royong. The attitudinal and motivational factors were found to contribute greatly towards the volunteers' commitment in RT activities. Political interest does not influence volunteers' commitment. Conclusion/Recommendation: The members' commitment in RT activities increases when they perceive that the instrumental values of RT are positive, find the activities in RT attractive, adopt a positive attitude towards RT activities and poses internal altruistic motivation. Research indicates there is a need to create neighborhood watch activities that are beneficial and attractive to ensure commitment from volunteers. Future studies can examine other organizational aspects of neighborhood watch such as administration, management, infrastructure and linkages with other related organization.
\end{abstract}

Key words: Commitment level, neighborhood community, positive attitude, motivational factors, volunteer residents, Rukun Tetangga (RT), altruistic motivation, RT attractive

\section{INTRODUCTION}

Development in middle-income developing countries through modernization process has witnessed rapid growth in the economy and material wealth, resulting in dramatic changes in the urban areas. This complex change process in the newly industrializing society has brought about dynamic social change amongst its urban inhabitants. Changes in the form of social relations in urban areas saw new social ties based on association and formal arrangements. As such the emergence of new social institutions is inevitable as new forms of association emerged in cities. These modernizing features of urban communities in developing countries rely on new forms of social solidarity. How do urban communities in developing countries overcome local issues?

Active citizenship in urban communities has become a central concept in the state policy agenda. The intent behind this agenda is vital in envisioning a strong, active and empowered community with increasing capability to do things for themselves, defining the problems they face and then solving them themselves (Annette, 2005). In fact, active citizenship entails more than simply increasing the level of public participation for its own sake, as it demands participation with a purpose. That purpose is to engage people in making their communities a better place for themselves and for those around them (Stoker, 2004).

Community involvement has a long history in the field of urban housing and became a popular theme in

Corresponding Author: Sivapalan Selvadurai, School of Social, Development and Environmental Studies,

Faculty of Social Sciences and Humanities, University Kebangsaan Malaysia,

Bangi 43600, Selangor, Malaysia Tel: 603-89213922 Fax: 603-89213334 
the regeneration of cities in the developed world (Rogers and Robinson, 2004). This movement has recently proliferated into other areas of social policy. In urban housing literature, the mechanisms for tenant participation and consultation have been in existence for many years. Community involvement and control of their neighborhood have led to the demise of the responsibilities of local authorities. These principles have also formed the basis of more recent policy initiatives, such as tenant participation in compact settlements and housing cooperatives (Rogers and Robinson, 2004; Blaug et al., 2006).

The need for community support and involvement in the successful design and implementation of policies formulated to address local problems was vital and the need for the spirit of volunteerism was crucial. Volunteering means any activity in which time is given freely to benefit another person, group, or organization. This definition does not preclude volunteers from benefiting from their work (Wilson, 2000). Volunteerism is typically proactive rather than reactive and entails some commitment of time and effort. Volunteerism amongst urban residents in an increasingly industrializing and modernizing experience in the developing countries is a growing field of studies.

Urban residents in Malaysia encounter many problems in their daily lives and safety is one of their main concerns. Recent spate of burglary and robbery in neighborhoods coupled with snatch thieve incidents have raised public outcry and alarm (Yeoh, 2010). The loss of faith on the police force to stamp the rise in domestic burglary and robbery incidents further aggravated the situation and created an atmosphere of fear or risk. Thus, it was very important for communities to organize voluntary association that can ensure the safety of the community as a whole. In Malaysia, Rukun Tetangga (RT) or Neighborhood Watch Committee was set up in 1975 by the Jabatan Perpaduan dan Intergrasi Nasional (JPNIN) or Department of National Unity and National Integration. Its main objective was to ensure neighborhood safety. Once RT is established in housing or neighborhood area, all the residents in that particular neighborhood area automatically becomes a member of RT (Department of National Unity and National Integration, Selangor, 2009). RT activities were organized voluntarily by the communities living within a neighborhood. The issue of high commitment volunteer culture amongst community participants is essential to ensure the success of neighborhood activities and also to maintain the role of RT as a vital organization to enhance the well being of the community within the particular neighborhood area. Its main function is to preserve, develop and strengthen the unity of the people and national integration in line with the government policy as enshrined in Federal Constitution and spelt out in RT program (Department of National Unity and National Integration, Selangor, 2009).

In 2001 a new approach on RT was introduced by the Department of National Unity and National Integration (JPNIN) that focuses on the community development concept (Department of National Unity and National Integration, Selangor, 2009). This approach encompasses activities such as socioeconomic, education, cultural and religious and others. The rationale for the new concept was to enable RT to play an active role in encouraging interaction and relationship within the community so as to enhance solidarity among the various ethnic groups. Community participation was vital to ensure the success of activities that had been carried out. Steers (1977) point out that higher commitment in organization activities will lead to greater desire and willingness to remain in the organization and increase in task performance. Therefore, greater community commitment is a key to the success of the voluntary participation in RT activities. Without commitment of the volunteers, activities that had been carried out can be left unattended (Ferris and Aranya, 1983; Porter et al., 2003). Commitment has been defined in several ways. This study adopts the organizational commitment concept as defined by Mowday et al. (1979), which were characterized by three features: strong belief in the acceptance of the values of organization goals; a willingness to work hard for the organization; and a strong desire to maintain membership in the organization.

For the activities implemented by RT to be successful, it also depends on attitude and motivational factors of participants that will influence volunteer commitment. Motivation has long been considered a crucial factor in distinguishing a long term volunteer from one who decides to stop volunteering (Chacon and Vecina, 2000). Many studies have shown that people who are involved in voluntary service as adaptable, sociable, have a sense of social belonging (Sundeen and Raskoff, 1994), politically participative (Hanks, 1981; Flanagan et al., 1998), motivated in civic engagement and supportive of prosocial norms (Youniss and Yates, 1997). Participation in the voluntary work were further encouraged by motivational factors such as altruism, religiosity, political ideology, culture values and egoism such as influence, status, economic interest and so forth. A study by McCracken (1991) among the 4BYouth leaders showed that commitment was characterized by individuals who placed more effort to ensure success in the organization, who were visionary 
and who were willing to work for society. Studies by McCracken (1991) and Rohs (1986) found that there was a significant relationship between attitudinal factors such as satisfaction, attraction and values towards volunteerism participation and commitment. Meanwhile, a local study shows that altruism and attractiveness of the 4B Youth was the best predictor of commitment towards volunteerism (McCracken, 1991). Studies have also shown that volunteers' commitment to their organizational activity was shaped by instrumental attitude such as the appropriateness of the activities to them, their keen interest in the activity, their skills and knowledge in a particular activity and their willingness to put extra effort in the activities that get involved (Muthuveloo and Rose, 2005; Moorthy et al., 2011). Motivational dimension such as altruistic values and learning interest contribute to student volunteering in most countries. The study also found that students who belong to egalitarian cultures were motivated to volunteer for altruistic reasons (Gronlund et al., 2011). Chacon and Vecina (2000) point out that, motivation was a crucial factor in distinguishing continuous long-term participation by volunteers than from those who decided to stop volunteering half-way down the line. For example, individual volunteer tended to learn and acquire capacities and competencies from organizational experience that were useful to them, after which they stop their volunteer services. This short-term behavior seems to be typical amongst the young volunteers due to their shared values (Marta and Pozzi, 2008). Volunteer relationship that creates social bonds among the people during their service activity affects their satisfaction and integration within the organization. This cohesive force leads to greater willingness to continue volunteerism and sustained participation in the organization (Omoto and Snyder, 1995; Wosinska et al., 2000). Meanwhile studies have shown that communities involvement in volunteering and neighborliness tend to strengthen communitie's and prevent child abuse ill-treatment. This involvement can have a strong psychological effect in creating a sense of neighborliness and a commitment to their community needs. Other factors such as knowledge, identity, ongoing activities, satisfaction and attitudes of volunteer have been found to influence integration of strong community initiatives (Haski-Leventhal et al., 2008).

There has been very little research done on the attitude and motivational factors that influence the commitment of people to participate in RT organization. The objectives of this stuyd were two-folds: (i) to examine the level of commitment of volunteer resident's participation in neighborhood watch organization and (ii) to identify attitudinal and motivational factors that influence their level of commitment.

\section{METERIALS AND METHODS}

Location of study area: RT Taman Sri Jelok is a residential area in an urban housing area in the state of Selangor, located in the central part of Peninsular Malaysia. RT Taman Sri Jelok comprised of 4 neighborhood areas namely: Taman Restu, Taman Sakap and Taman Jelok Ria and Taman Sri Jelok. RT Taman Sri Jelok was recognized by the Department of National Unity and National Integration or Jabatan Perpaduan dan Integrasi Nasional (JPNIN) as one of the most active RT in Hulu Langat, Selangor, Malaysia. These residential areas have more than 2000 inhabitants, comprised of 50\% Malays, 30\% Indian and 20\% Chinese (Department of National Unity and National Integration, 2004).

Data collection: A census survey on all the volunteer residents of the neighborhood watch scheme at RT Taman Sri Jelok was carried out. The names were obtained from the RT name list to ensure only volunteer residents were involved in the activities. The data were collected by using questionnaire instrument. After obtaining their names and addresses, a set of questionnaire was distributed to each of the volunteered residents. The researcher was assisted by the chairman and committee members of the RT in distributing the questionnaire. From the 252 volunteer residents names listed in the R.T, the researcher managed to distribute 223 questionnaires. The remaining prospective respondents cannot be reached due to relocation from the present neighborhood or were not available at the time of the distribution. Distribution of questionnaire was carried out for a month due to the respondents working schedule and busy with their personnel matters. Each respondent was given one week to fill in the questionnaires. About 211 of the questionnaires were returned and only 200 questionnaires were adequately completed.

Data analysis: The data were coded and scores for the level of volunteer commitment were analyzed by way of descriptive frequencies and measures of central tendency appropriate for the type of data. Correlation technique was employed to establish the direction and strength of the relationships between the independent variables (motivation factors and attitudinal factors) and dependent variables (level of commitment). The level of the strength between the independent and dependent variables were measured using Guilford's Rule of Thumb (Guilford and Ruchter, 1973). 


\section{RESULTS}

Level of commitment: The results show that in general, volunteers were highly committed to RT activities. The most frequent response to the commitment measure was "agree" and "strongly agree." Majority $(85.5 \%)$ of the volunteers believe RT goals and values were suitable to cultivate solidarity within the neighborhood. For example the role played by RT in promoting harmony within the community through "gotong-royong" or mutual cooperation among local residents has been able to attain positive shared values (Thompson, 2004). These values appear to have been cultivated in the community through RT activities. Community volunteers were also willing to put in extra efforts to ensure that the activities are carried out successfully and willingness to remain in the organization. This social bond resonates Porter's (Ferris and Aranya, 1983) assertion of organizational commitment.

\section{Factors influencing level of commitment:}

Attitude: Four variables under attitudinal factors were examined namely: the instrumental value of RT perceived by the individual, the attractiveness of RT, attitude of an individual towards RT activities and satisfaction from volunteer work. The result shows that instrumental values of RT and attractiveness of RT contribute greatly to commitment. Volunteer residents feel that RT encourage them to foster harmony in the neighborhood and the attractiveness of the activities carried out satisfy them generally. Most of the volunteer resident stated that they are satisfied doing volunteering work with other races. The results show that there was a strong correlation between the all attitudinal factors in influencing commitment of volunteers (Table 1).

Motivation: Five variables under the motivational factors are altruism, egoism, social obligation, religiosity and political interest. The results show that four out of five motivational variables had a significance relationship with commitment (Table 2). Altruism, egoism and social obligation were important motivational factors that influence commitment of volunteer residents in RT activities. Gotong-royong or mutual cooperation spirit embedded in most RT activities enhanced the volunteer residents' altruistic values. Previous studies also showed that volunteers involved in voluntary activities were drawn by altruistic values. Egoism attributes such as to get new personal experience by doing volunteer work and to get new skill in other fields also motivated them to engage in such activities.
Table 1: Pearson correlation of attitudinal variables and community commitment to RT

\begin{tabular}{|c|c|c|}
\hline \multirow[b]{2}{*}{ Independent variables } & \multicolumn{2}{|c|}{$\begin{array}{l}\text { Dependent variables } \\
\text { commitment toward RT activities }\end{array}$} \\
\hline & $\mathrm{r}$ & $\mathrm{p}$ \\
\hline Instrumental values & 0.74 & 0.000 \\
\hline Attractiveness of RT activities & 0.74 & 0.000 \\
\hline Attitude towards RT activities & 0.69 & 0.000 \\
\hline Satisfaction towards RT activities & 0.70 & 0.000 \\
\hline
\end{tabular}

Table 2: Pearson correlation of motivation variables and community commitment to RT

\begin{tabular}{lll}
\hline & $\begin{array}{l}\text { Dependent variables } \\
\text { commitment toward RT activities }\end{array}$ & $\mathrm{p}$ \\
\hline Independent variables & $\mathrm{r}$ & 0.000 \\
Altruisme & 0.61 & 0.000 \\
Egoism & 0.52 & 0.000 \\
Religiousity & 0.39 & 0.000 \\
Social obligation & 0.52 & 0.060 \\
Political interest & 0.13 & \\
Note: Two tail significant, $\mathrm{p} \leq 0.05$ Scale: A 4-point Likert scale was \\
used to measure the perceived value: $1=$ strongly disagree 2 \\
disagree; 3 = agree; 4 = strongly agree
\end{tabular}

Volunteer residents also felt that, it is their obligation to help the community in RT Taman Sri Jelok, especially in preserving the state of security of residents, besides the need to cultivate and preserve solidarity in the neighborhood.

\section{DISCUSSION}

The high levels of commitment shown by the volunteer residents toward RT activities have been significantly influenced by the attitudinal factors. As such neighborhood watch programs should be designed to benefit the residents in fulfilling their needs and aspirations as well as make their activities more attractive. Meanwhile, the motivation aspects such as sense of neighborhood solidarity, harmonious living provides incentive for voluntarism. Though neighborhood watch schemes appear modern in its manifest form, but the spirit of active citizenship can be activated by the spirit of commitment voluntarism. To enhance the voluntarism among the residents, various stakeholders like local authority, police and informal religious and cultural institutions within the locality have to be coordinated to ensure success. Also institutional mechanisms such as enabling policies in the form of grants for residents association and restrictions in the form of gated neighborhood scheme can play a role in enhancing resident's commitment towards voluntarism. 


\section{CONCLUSION}

The high level of commitment was necessary for sustaining voluntary neighborhood watch organization such as RT. The high level of commitment shown by volunteer residents should be cultivated. In addition, activities fulfilling the needs of the current and future generation without sacrificing the gotong-royong values should be planned continuity. The study also shows the need and the aspirations of the residents are addressed to ensure sustained interest and engage in mere activities of mutual benefits.

This implies that local leaders must be willing to strive hard to ensure that the organization meets the needs of volunteer residents. These leaders must always be aware that the activities must be suitable with the community needs. The instrumental values of volunteers can contribute indirectly to increase participation in neighborhood activities. Future studies can examine different independent variables such as administration, management, infrastructure and linkages with other neighborhood programs that can influence the commitment of urban residents to volunteerism. Commitment studies can also be expanded to examine gender empowerment and sustaining cultural values. In addition phenomenological approach to understand the urban communities' needs and wants can elicit insights into the commitment of residents in volunteerism.

\section{REFERENCES}

Annette, J., 2005. Character, civic renewal and service learning for democratic citizenship in higher education. Bri. J. Educ. Stud., 53: 326-340. DOI: $10.1111 /$ j.1467-8527.2005.00298.x

Blaug, R., L. Horner, A. Kenyon and R. Lekhi, 2006. Public Value and Local Communities: A Literature Review. The Work Foundation, London, pp: 68,

Chacon, F. and M.L. Vecina, 2000. Motivation and burnout in volunteerism. Psychology Spain, 4: 7581.

Department of National Unity and National Integration, Selangor, 2009. Pengenalan Skim Rukun Tetangga. In Malay.

Ferris, K.R. and N. Aranya, 1983. A comparison of two organizational commitment scales. Personnel Psychol., 36: 87-98. DOI: $10.1111 / \mathrm{j} .1744-$ 6570.1983.tb00505.x

Flanagan, C.A., J.M. Bowes, B. Jonsson, B. Csapo and E. Sheblanova, 1998. Ties that bind: Correlates of adolescents' civic commitment in seven countries. J. Soc. Iss., 54: 457-476.
Gronlund, H., K. Holmes, C. Kang, R.A. Cnaan and F. Handy et al., 2011. Cultural values and volunteering: A cross-cultural comparison of students' motivation to volunteer in 13 countries. J. Acad. Ethics, 9: 87-106. DOI: 10.1007/s10805011-9131-6

Guilford, J.P. and B. Ruchter, 1973. Fundamental Statistics in Psychology and Education. 5th Edn., McGraw-Hill Book Company, New York, ISBN: 0070251487, pp: 546.

Hanks, M., 1981. Youth, voluntary association and political socialization. Soc. Forces, 60: 211-233.

Haski-Leventhal, D., A. Ben-Arieh and G.B. Melton, 2008. Between neighborliness and volunteerism: Participants in the strong communities initiative. Family Community Health, 31: 150-161. DOI: 10.1097/01.FCH.0000314575.58905.a1

Marta, E. and M. Pozzi, 2008. Young people and volunteerism: A model of sustained volunteerism during the transition to adulthood. J. Adult Dev., 15: 35-46. DOI: 10.1007/s10804-007-9033-4

McCracken, J.D., 1991. Commitment of 4-B (Malaysia) Youth Leaders Towards Volunteerism. 1st Edn., Ohio State University, US., pp: 360.

Moorthy, R., A.C. Er, S. Selvadurai and N. Lyndon, 2011. Bioethics principles in the teaching of climate change. Am. J. Applied Sci., 8: 962-966, DOI: 10.3844/ajassp.2011.962.966

Mowday, R.T., R.M. Steers and L.W. Porter, 1979. The measurement of organizational commitment. J. Vocat. Behav., 14: 224-247. DOI: 10.1016/00018791(79)90072-1

Muthuveloo, R. and R.C. Rose, 2005. Antecedents and Outcomes of organisational commitment among Malaysian engineers. Am. J. Applied Sci., 2: 10951100. DOI: 10.3844/ajassp.2005.1095.1100.

Omoto, A. M. and M. Snyder, 1995. Sustained helping without obligation: Motivation, longevity of service and perceived attitude change among AIDS volunteers. J. Personality Soc. Psychol., 68: 671686. DOI: 10.1037/0022-3514.68.4.671

Porter, L.W., G.A. Bigley and R.M. Steers, 2003. Motivation and Work Behavior. 7th Edn., McGraw- Hill Book Company, New York, ISBN: 0071131027, pp: 635.

Rogers, B. and E. Robinson, 2004. The benefits of community engagement: A review of the evidence. Home Office, London, pp: 64.

Rohs, F.R., 1986. Social background, personality, and attitudinal factors influencing the decision to volunteer and level of involvement among adult 4H leaders. Nonprofit Voluntary Sector Q., 15: 8799. DOI: $10.1177 / 089976408601500106$ 
Steers, R.M., 1977. Antecedents and outcomes of organizational commitment. Admin. Sci. Q., 22: 46-56.

Stoker, G., 2004. Transforming Local Governance: From Thatcherism to New Labour. 1st Edn., Palgrave Macmillan, New York, ISBN: 9780333802489, pp: 250.

Sundeen, R.A. and S.A. Raskoff, 1994. Volunteering among teenagers in the United States. Nonprofit Voluntary Sector Q., 23: 383-403. DOI: 10.1177/089976409402300407

Thompson, E.C., 2004. Rural villages as socially urban spaces in Malaysia. Urban Stud., 41: 2357-2376. DOI: 10.1080/00420980412331297573
Wilson, J., 2000. Volunteering. Annual Rev. Sociol., 26: 215-40. DOI: 10.1146/annurev.soc.26.1.215

Wosinska, W., R.B. Cialdini, D.W. Barrett and J. Reykowski, 2000. The Practice of Social Influence in Multiple Cultures. 1st Edn., Psychology Press, ISBN-10: 0805832793, pp: 400.

Yeoh, T., 2010. Safety in the Cities.

Youniss, J. and M. Yates, 1997. Community Service and Social Responsibility in Youth. 1st Edn., University of Chicago Press, Chicago, ISBN: 9780226964836, pp: 185. 